\title{
Attachment Style and the Association of Spanking and Child Externalizing Behavior
}

\author{
Kaitlin P. Ward, MSW; Shawna J. Lee, PhD; Garrett T. Pace, MSW; \\ Andrew Grogan-Kaylor, PhD; Julie Ma, PhD
}

From the School of Social Work, Department of Psychology, University of Michigan (KP Ward), Ann Arbor, Mich; School of Social Work, University of Michigan (SJ Lee, A Grogan-Kaylor), Ann Arbor, Mich; School of Social Work, Department of Sociology, University of Michigan (GT Pace), Ann Arbor, Mich; and School of Social Work, University of Michigan-Flint (J Ma), Flint, Mich

The authors have no conflicts of interest to disclose.

Address correspondence to Kaitlin P. Ward, University of Michigan, School of Social Work, 1080 S University Ave, Ann Arbor, MI 48109 (e-mail: kpward@umich.edu).

Received for publication April 9, 2019; accepted June 28, 2019.

\section{Abstract}

OBJECTIVE: To examine whether the longitudinal associations between maternal spanking and child externalizing behavior are moderated by attachment style.

MethoDS: This study used data from the Fragile Families and Child Wellbeing Study $(\mathrm{n}=2211)$, a large cohort sample of low-income urban families. Multiple-group autoregressive cross-lagged models examined the associations between maternal spanking and child externalizing behavior when children were ages 1,3 , and 5 . Moderation by attachment style was examined using structural invariance testing.

RESULTS: For children with an insecure mother-child attachment style, spanking at age 1 was associated with externalizing behavior at age 3 . However, for children with a secure motherchild attachment style, the association between maternal spanking at age 1 and child externalizing behavior at age 3 was absent. Attachment style did not moderate the association between maternal spanking at age 3 and externalizing behavior at age 5, suggesting that spanking at age 3 is associated with deleterious outcomes at age 5 , regardless of attachment style.

Conclusions: Results suggest that even in the context of a secure attachment style, spanking is associated with adverse outcomes in early childhood. Findings support the American Academy of Pediatrics 2018 policy statement, which encourages parents to avoid spanking when disciplining children. Results suggest that children, regardless of attachment style, may benefit from policies and services that promote non-violent forms of discipline.

KeYwords: attachment; physical punishment; spanking; physical discipline; parenting

Academic Pediatrics 2020;20:501-507

\section{WhAT'S NEW}

Maternal spanking at age 3 is associated with child externalizing behavior at age 5, regardless of motherchild attachment style. Even in the context of a secure mother-child attachment, spanking is associated with deleterious outcomes.

WhEN ATTEMPTING TO discipline children, teach children proper social conduct, or get children to listen, some parents choose to use physical punishment, meaning they smack, slap, or spank their children in response to unwanted behaviors in an attempt to improve their children's behavior in the future. In November 2018, the American Academy of Pediatrics (AAP) released a policy statement urging parents to avoid physical punishment when disciplining children. ${ }^{1}$ This statement is substantially stronger than the AAP's 1998 “Guidance for Effective Discipline" report, which encouraged parents to develop methods other than spanking when disciplining children. ${ }^{2}$ This change in AAP recommendations was supported by research findings showing physical punishment to be associated with a host of negative socioemotional child outcomes. $^{3-5}$

Some parents increasingly deem physical punishment to be an unacceptable form of discipline. ${ }^{6,7}$ At the same time, the most recent General Social Survey suggests approximately $70 \%$ of American adults agree that it is sometimes necessary to discipline a child by spanking. ${ }^{8}$ A representative survey of US parents showed that the majority of young children are spanked by their parents. In 2014, approximately $65 \%$ of children ages 2 to 4 were spanked, a decline of only $11 \%$ from 1995 when approximately $76 \%$ of children ages 2 to 4 were spanked. ${ }^{9}$ Many parents continue to use physical punishment for a variety of reasons, for example, believing that, in the context of an otherwise loving parent-child relationship, physical punishment is unlikely to be harmful to children. ${ }^{10}$ These "conditional corporal punishment" arguments are based on the premise that there are potential moderators 
of the relationship between physical punishment and negative child outcomes, in that certain conditions or contexts may mitigate the negative consequences of physical punishment.

In light of the conditional corporal punishment arguments, an argument can be made that a secure attachment style may buffer the adverse impact of spanking on negative child outcomes. Attachment style refers to the type of relationship children have with their parent(s). ${ }^{11}$ Children with secure attachment styles have parents who respond promptly and sensitively to their child's needs, yet also provide appropriate room for exploration. ${ }^{12}$ Thus, these children learn they can rely on their parents to meet their emotional and physical needs. Children with insecure attachment styles, on the other hand, have parents who either do not respond or respond inconsistently to their child's needs, and may provide too little or too much room for exploration. ${ }^{12}$ Consequently, children with insecure attachment styles learn they cannot rely on their parents to consistently meet their emotional and physical needs and are at higher risk for later maladjustment. ${ }^{13-15}$

From theorizing concerning the conditional effects of corporal punishment, ${ }^{10}$ maternal spanking may be more problematic in the context of an insecure attachment style, whereas secure parent-child attachment could buffer children from harsh parenting behaviors. ${ }^{16}$ Even so, other theoretical frameworks, such as social learning theory, argue that the modeling of aggressive behavior (ie, maternal spanking) would increase children's aggressive behavior over the long run. ${ }^{17}$ Indeed, the associations between spanking and child externalizing behavior have been consistently found in the spanking literature. ${ }^{4}$ Empirical evidence suggests that these associations are largely consistent across multiple contexts, ${ }^{4}$ even when the motherchild relationship is high in warmth. ${ }^{18,19}$ Yet, to our knowledge, no study has simultaneously examined maternal spanking and attachment style and their associations with child externalizing behavior. The current study examines whether attachment style moderates the relationship between spanking and externalizing behavior over the first 5 years of life among a large, diverse sample of urban families. Based on prior research ${ }^{18,19}$ and acknowledging competing theoretical frameworks regarding the mechanisms linking maternal spanking to child wellbeing, we hypothesized that spanking would be related to higher levels of child externalizing behavior, regardless of mother-child attachment style.

\section{Methods}

\section{Participants}

Data came from the Fragile Families and Child Wellbeing Study (FFCWS), a population-based birth cohort study of 4,898 children from 20 US cities with a population of 200,000 or more. ${ }^{20,21}$ Nonmarital births were oversampled. Due to this sampling strategy, FFCWS is more urban, disadvantaged, and racially diverse than the overall US population. Parents were first interviewed at the time of the focal child's birth between 1998 and 2000. Subsequent waves of data were collected when the focal child was age 1,3 , and 5 . When the focal child was age 3 and 5, an In-Home Longitudinal Study of PreSchool-aged Children ("In-Home study") was conducted, during which a parent interview, child assessment, and an interviewer observation were conducted. Child attachment style and externalizing behavior were measured during the In-Home study at age 3. Only children who had their attachment style assessed and lived with their mother at age 1 were included in the current study $(\mathrm{n}=2,211)$. The Institutional Review Board (IRB) at Columbia University and Princeton University approved all participant procedures and data collection for the FFCWS. The IRB at the University of Michigan considered our secondary analysis of these data exempt.

\section{Measures}

Independent Variable: Maternal Spanking at Ages 1, 3 , AND 5

Maternal spanking was measured by asking mothers the following question: "Sometimes children behave pretty well and sometimes they don't. In the past month, have you spanked (child) because (he/she) was misbehaving or acting up?" If mothers responded "yes," a subsequent question was asked regarding the frequency of spanking. We collapsed these responses into one predictor variable measuring the frequency of spanking at ages 1,3 , and 5 $(0=$ never in the past month, $1=$ only once, twice, or a few times in the past month, $2=a$ few times a week or every day in the past month).

\section{Dependent Variable: Child Externalizing Behavior at AGES 3 AND 5}

Child externalizing behavior was measured using the Child Behavior Checklist (CBCL). ${ }^{22}$ On a scale from 0 (not true) to 2 (very true or often true), mothers assessed child behaviors such as being defiant, disobedient, demanding, whiny, selfish, throwing temper tantrums, screaming, hitting others, and getting into fights. When children were 3 years old, the 15 -item CBCL/2-3 was used $(\alpha=.86)$. When children were 5 years old, the 20-item CBCL/4-18 was used $(\alpha=.85)$. We calculated the mean score of the CBCL items to measure externalizing behavior.

\section{Moderator: Attachment at Age 3}

Mother-child attachment style was measured using an FFCWS-adapted version of the Attachment Q-Sort ${ }^{23}$ when the child was 3 years old. The Attachment Q-sort has shown convergent validity with the Stange Situation Procedure, the gold standard for measuring mother-child attachment. ${ }^{24}$ Although attachment was only measured at age 3, prior research suggests attachment patterns are considerably consistent in early childhood. ${ }^{25}$ The Q-Sort involved mothers sorting 39 cards with descriptions of child behavior into 5 piles, ranging from 1 (applies mostly) to 5 (rarely or hardly ever). Examples of items on the cards include the child being clingy, rarely going 
to the mother for help, and exploring freely in unfamiliar places. Cases were classified into 3 categories: secure, insecure-avoidant, and insecure-resistant. These categories were dichotomized to reflect whether the child had a secure or insecure attachment.

\section{Maternal Sociodemographic Characteristics}

A number of maternal characteristics that are associated with spanking and child externalizing behavior were included in the analysis. Maternal marital status $(0=n o t$ married, $1=$ married $)$ and whether the mother was cohabitating with the child's biological father $(0=n o, 1=y e s)$ were dichotomously coded. Maternal age was measured in years. Maternal race (Hispanic, White, Black, and other) was dichotomously coded, and Black was used as the comparison category. Each level of maternal education level (less than high school, high school degree, some college, and college degree) was dichotomously coded, and high school degree was used as the comparison category. Mother-reported household income was a continuous variable that assessed the income of all individuals in the household over the past year. Maternal depression was measured using the 8-item Composite International Diagnostic Interview-Short Form, ${ }^{26}$ which measures the likelihood of being diagnosed with major depression if participants would have been given the full Composite International Interview $(0=$ unlikely, $1=$ likely $)$. Maternal parenting stress was measured using a composite of 4 items rated from 1 (strongly agree) to 4 (strongly disagree). We reverse-coded responses so that higher values indicated higher parenting stress. Examples of parenting stress items include "Being a parent is harder than I thought it would be" and "I feel trapped by my responsibilities as a parent."

\section{Child Characteristics at Age 1}

Two child characteristics were controlled for, namely sex and temperament. Sex was dichotomously coded $(0=$ female $; 1=$ male $)$. Child temperament served as an early measure of child externalizing behavior, and was measured at age 1 using the 3 externalizing items from the Emotionality, Activity, and Sociability (EAS) Temperament Survey for Children. ${ }^{27}$ On a scale from 1 (not at all like my child) to 5 (very much like my child), mothers rated whether the child gets upset easily, reacts strongly when upset, and often fusses and cries $(\alpha=.60)$.

\section{Statistical Analysis}

Bivariate and descriptive statistics were conducted in Stata version 15.1. All other statistical analyses were conducted in Mplus version $8 .^{28} \mathrm{We}$ screened for missing data on our key variables of interest. Less than $1 \%$ of data were missing for child externalizing behavior at age 3, and $15.1 \%$ of data were missing for child externalizing behavior at age 5 . Approximately $3.8 \%$, less than $1 \%$, and $5.7 \%$ of data were missing for maternal spanking at ages 1,3 , and 5 , respectively. Due to the relatively small amount of missing data, and in order to use all available data in analyses, full-information maximum likelihood estimation was utilized. Full-information maximum likelihood has been documented as an appropriate and generally unbiased method for handling missing data. ${ }^{29}$

Multiple-group bivariate autoregressive cross-lagged models were conducted to examine the longitudinal association between maternal spanking and child externalizing behavior. The Mplus cluster option was used to account for participants being clustered within 20 US cities. To determine whether spanking influenced externalizing behavior differently for secure and insecure attachment groups, structural invariance was tested. More specifically, the cross lagged paths from maternal spanking at age 1 predicting child externalizing behavior at age 3, and maternal spanking at age 3 predicting child externalizing behavior at age 5 , were constrained to examine whether there was statistical evidence of structural invariance across the 2 groups (secure and insecure attachment). To note, the cross lagged path from maternal spanking at age 3 to child externalizing behavior at 5 held child externalizing behavior at age 3 constant; the cross lagged path from maternal spanking at age 1 to child externalizing behavior at age 3 held externalizing temperament at age 1 constant.

The comparative fit index (CFI), root mean square error of approximation (RMSEA), and the $\chi^{2}$ difference test $\left(\chi^{2} \Delta\right)$ were used to determine whether the constrained or unconstrained model better fit the data. CFI values close to .95 and RMSEA values below .08 indicate good fit. Because Mplus uses the MLR (maximum likelihood with robust standard errors) estimator, the chi-square difference test was conducted by incorporating the difference-test scaling correction. As explained by Satorra and Bentler, ${ }^{30}$ when nested models are tested with MLR, the difference between the 2 models are not distributed as a typical chisquare distribution and thus need to be adjusted. A significant $\chi^{2} \Delta$ would indicate that the nonnested model (ie, the unconstrained model) better fit the data.

\section{ResULtS}

At age 1, about $27.45 \%$ of children were spanked at least once in the past month. Spanking peaked at age 3, when more than half of children $(54.82 \%)$ were spanked at least once in the past month. By age 5, spanking declined slightly, with $47.76 \%$ of children spanked in the past month. There were $542(24.51 \%)$ insecurely attached and $1,669(75.49 \%)$ securely attached children in this sample. Bivariate analyses indicated no significant differences in maternal spanking at ages 1 and 3 based on attachment style (see Table 1).

Compared to children with insecure attachment styles, children with secure attachment styles exhibited less externalizing behavior at ages $3(P<.001)$ and $5(P<$ $.001)$. Furthermore, children with secure attachment styles were more likely to have mothers cohabitating with their biological fathers $(P=.029)$, were more likely to have mothers in the "no depression" category $(P=.001)$, were more likely to be female $(P=.017)$, and were rated by mothers to have a lower externalizing temperament at age $1(P<.001)$. 
Table 1. Bivariate Analyses of Study Variables by Attachment Style

\begin{tabular}{|c|c|c|c|c|}
\hline & \multirow{2}{*}{$\frac{\text { Total Sample }}{(\mathrm{N}=2211)}$} & \multicolumn{2}{|c|}{ Attachment Style } & \multirow[b]{2}{*}{$P$} \\
\hline & & Insecure $(n=542)$ & Secure $(n=1669)$ & \\
\hline Maternal spanking, age $1, \%$ & & & & .270 \\
\hline 0 times in the past month & 72.45 & 68.81 & 72.32 & \\
\hline $1-3$ times in the past month & 21.97 & 24.39 & 21.16 & \\
\hline Few times or every day in the past month & 6.59 & 6.81 & 6.51 & \\
\hline Maternal spanking, age 3, \% & & & & .213 \\
\hline 0 times in the past month & 45.03 & 41.85 & 46.07 & \\
\hline $1-3$ times in the past month & 42.81 & 44.81 & 42.16 & \\
\hline Few times or every day in the past month & 12.15 & 13.33 & 11.77 & \\
\hline Maternal spanking, age $5, \%$ & & & & .024 \\
\hline 0 times in the past month & 49.35 & 50.20 & 49.08 & \\
\hline $1-3$ times in the past month & 45.32 & 42.29 & 46.30 & \\
\hline Few times or every day in the past month & 5.32 & 7.51 & 4.62 & \\
\hline Child externalizing behavior, age 3 & 0.66 & 0.87 & 0.59 & $<.001$ \\
\hline Child externalizing behavior, age 5 & 0.56 & 0.68 & 0.52 & $<.001$ \\
\hline Maternal marital status, $\%$ & & & & .213 \\
\hline Married & 21.85 & 19.92 & 77.53 & \\
\hline Unmarried & 78.15 & 80.07 & 22.47 & \\
\hline Maternal cohabitation with biological father, \% & & & & .029 \\
\hline Cohabitating & 36.77 & 32.84 & 38.05 & \\
\hline Not cohabitating & 63.23 & 67.16 & 61.95 & \\
\hline Maternal age & 24.98 & 24.75 & 25.06 & .297 \\
\hline \multicolumn{5}{|l|}{ Maternal race, \% } \\
\hline Hispanic & 22.11 & 21.40 & 22.34 & .647 \\
\hline White & 20.39 & 20.11 & 20.48 & .853 \\
\hline Other & 3.17 & 2.21 & 3.48 & .143 \\
\hline Black & 54.33 & 56.27 & 53.69 & .295 \\
\hline \multicolumn{5}{|l|}{ Maternal education, \% } \\
\hline Less than high school & 34.01 & 38.19 & 32.65 & .018 \\
\hline High school & 31.61 & 28.97 & 32.47 & .127 \\
\hline Some college & 24.95 & 23.62 & 25.39 & .407 \\
\hline College graduate & 9.42 & 9.23 & 9.48 & .858 \\
\hline Maternal household income & 3.25 & 3.14 & 3.28 & .411 \\
\hline Maternal depression, $\%$ & & & & .001 \\
\hline Yes & 21.67 & 20.15 & 14.02 & \\
\hline No & 78.33 & 79.85 & 85.98 & \\
\hline Maternal parenting stress & 2.73 & 2.62 & 2.77 & $<.001$ \\
\hline Child sex, \% & & & & .017 \\
\hline Male & 51.65 & 56.09 & 50.21 & \\
\hline Female & 48.35 & 43.91 & 49.79 & \\
\hline Child temperament & 1.84 & 2.10 & 1.76 & $<.001$ \\
\hline
\end{tabular}

Results are reported as means, unless otherwise specified. Range of maternal age is 15-43; range of maternal income is $0-50$ (in units of 10,000 US dollars); range of parenting stress is $1-4 . \chi^{2}$ tests were used for categorical variables, and t-tests were used for continuous and dichotomous variables.

\section{Structural InVAriance Testing}

When comparing the constrained and unconstrained models, model fit indices suggested that the unconstrained model better fit the data (constrained: $\mathrm{CFI}=.92$, RMSEA $=.04$; unconstrained: $\mathrm{CFI}=.94$, RMSEA $=.03$ ). The chi-square difference test was significant (correction difference $=2.12, \chi^{2} \Delta=22.08, \Delta \mathrm{P}=2$ ), confirming that the unconstrained model fit the data better than the constrained model. These results suggest structural variance across the groups; that is, the longitudinal associations between maternal spanking and child externalizing behavior were different for securely attached and insecurely attached children.

\section{Unconstrained Autoregressive Path Model Results}

Results from the multiple-group unconstrained autoregressive cross-lagged path models can be found in the Figure. All analyses controlled for maternal age, race, education level, depression, parenting stress, mother-reported household income, whether the mother was cohabitating with or married to the child's biological father, child sex, and child temperament. For both groups, child temperament at age 1 significantly predicted externalizing behavior at age 3 (secure: $\beta=.25, P<.001$; insecure: $\beta=.21, P<$ .001 ), and externalizing behavior at age 3 significantly predicted externalizing behavior at age 5 (secure: $\beta=.45, P<.001$; insecure: $\beta=.51, P<.001)$. For both groups, maternal spanking at age 1 significantly predicted maternal spanking at age 3 (secure: $\beta=.33$, $P<.001$; insecure: $\beta=.32, P<.001$ ), and maternal spanking at age 3 significantly predicted maternal spanking at age 5 (secure: $\beta=.37, P<.001$; insecure: $\beta=.35, P<.001)$. 
Age 1

Age 3

Age 5

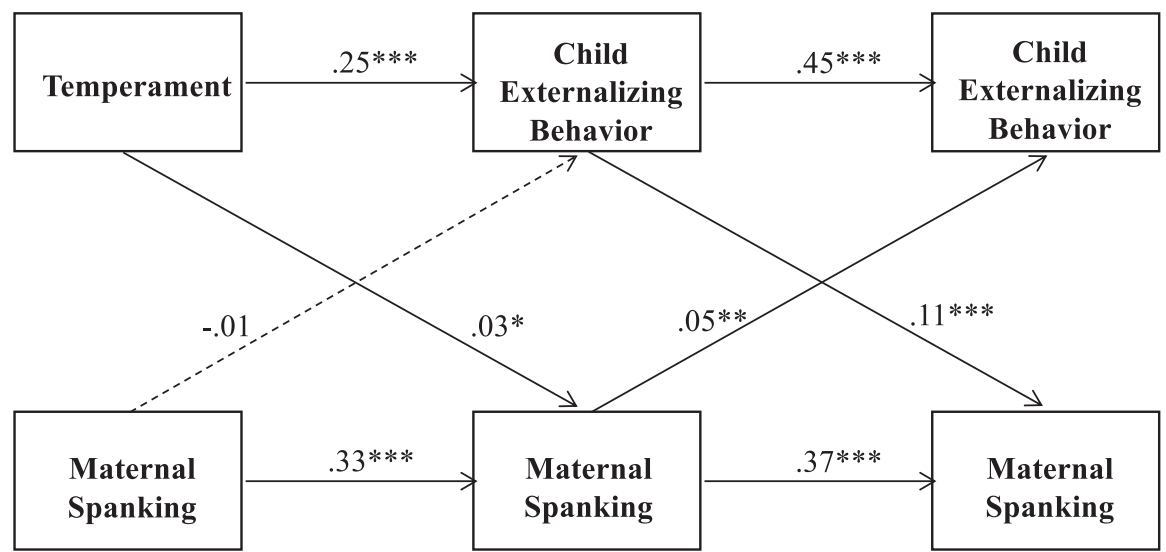

B Insecure Attachment

Age 1 Age 3 Age 5

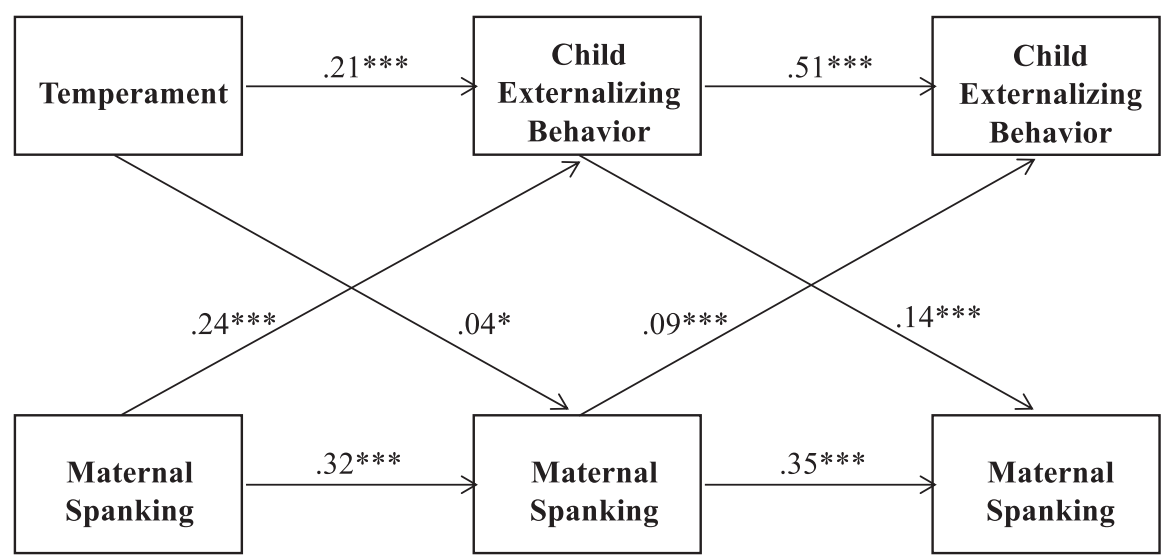

Figure. Multiple-group autoregressive cross-lagged models depicting the relationship between maternal spanking and child externalizing behavior across children with a secure and insecure attachment to their mothers. (A) Depicts results from the securely attached group, and (B) depicts results from the insecurely attached group. Standardized coefficients are shown. Maternal marital status, whether the mother was cohabitating with the child's biological father, maternal age, maternal race, maternal education level, mother-reported household income, maternal depression, maternal parenting stress, and child sex were controlled in these models. ${ }^{\star} \mathrm{P}<.05,{ }^{\star \star} \mathrm{P}<.01,{ }^{\star \star *} \mathrm{P}<.001$.

\section{Unconstrained Cross-Lagged Path Model Results}

Coefficients from the unconstrained cross-lagged model revealed some significant differences between spanking and externalizing behavior based on attachment style. For children with an insecure attachment style, maternal spanking at age 1 significantly predicted externalizing behavior at age $3(\beta=.24, P<.001)$. For children with a secure attachment style, maternal spanking at age 1 did not significantly predict externalizing behavior at age 3 ( $\beta=-.01, P=.818$ ). However, for both groups, maternal spanking at age 3 significantly predicted externalizing behavior at age 5 (secure: $\beta=.05, P=.004$; insecure: $\beta=.09, P<.001)$. For the insecurely attached group, the final model accounted for $19.7 \%$ and $36.8 \%$ of the variability in externalizing behavior at ages 3 and 5, respectively. For the securely attached group, the final model accounted for $15.8 \%$ and $29.3 \%$ of the variability in externalizing behavior at ages 3 and 5 , respectively.

\section{Discussion}

The AAP recently recommended that parents and caregivers avoid the use of physical punishment of children, yet the majority of parents in the $\mathrm{US}^{4}$ and worldwide ${ }^{31}$ 
use physical punishment. Thus, it is increasingly important for pediatricians and other professionals to understand how to respond to arguments they are likely to hear that support the use of physical punishment. One of those arguments is that spanking is not harmful in the context of an otherwise loving and warm parent-child relationship. ${ }^{10}$ Given the centrality of attachment to early childhood development, a secure attachment style is considered to be an important protective factor for adverse child outcomes $^{13,14}$. At the same time, other theoretical frameworks suggest that the parents' modeling of aggression is likely to teach children that aggression is one way to solve problems. ${ }^{17}$

Study results indicated that levels of spanking at age 1 and age 3 did not differ based on attachment style. This finding is consistent with prior research showing that maternal use of spanking does not differ by level of maternal warmth ${ }^{18,19}$ or mother-child attachment style. ${ }^{32}$ Practically speaking, this means that professionals should be counseling all parents against the use of physical punishment, not just those parents who may appear to have a more disrupted parent-child attachment.

Second, secure attachment buffered the longitudinal relationship between maternal spanking at age 1 and externalizing behavior at age 3 . That is, for children with an insecure mother-child attachment style, spanking at age 1 was associated with externalizing behavior at age 3 . However, for children with a secure mother-child attachment style, this relationship was not statistically significant: spanking at age 1 was not associated with externalizing behavior at age 3 . No such buffering effect was seen in the association between maternal spanking at age 3 and externalizing behavior at age 5, suggesting that spanking at age 3 is associated with deleterious outcomes at age 5 , regardless of mother-child attachment style. These findings are particularly important, because the large majority of children nearly $55 \%$ in this study - were spanked at age 3 . This age is also a time when parents seek advice from pediatricians and other professionals about how to discipline their children, as child misbehavior tends to heighten during the preschool years. ${ }^{33}$ As a whole, our findings suggest that a secure mother-child attachment may serve as a protective factor of spanking at younger ages, but not in the longer term. Thus, pediatricians can confidently counsel parents against the use of physical punishment.

\section{LIMITATIONS}

A number of limitations must be noted. First, spanking and child behavior problems were based on maternal report, which may be subject to social desirability reporting bias. For example, research indicates that mothers tend to underestimate their use of spanking. ${ }^{34}$ It would be ideal to include measures from multiple reporters; however, these were not available in the FFCWS. Second, spanking from other caregivers, such as fathers, was not accounted for. That said, prior research indicates that paternal spanking does not seem to have the same negative longitudinal associations with child outcomes as have been demonstrated with maternal spanking, ${ }^{35}$ thus justifying the focus on maternal spanking. Along a similar vein, FFCWS did not measure child externalizing behavior at age 1. However, we controlled for child negative emotional temperament at age 1, as has been done in prior FFCWS studies. ${ }^{33}$ Child negative emotional temperament is well established as a precursor to child behavior problems, and is also associated with parental spanking. ${ }^{33}$

The children in our sample disproportionately came from lower-income families in urban areas; consequently, our sample is not generalizable to all children in the US. Although analyses controlled for a number of important child and maternal characteristics, there could be other omitted confounding variables that may influence spanking as well as child externalizing behavior; therefore, causal conclusions should not be made. Future research may benefit from other types of analyses that focus more directly on causality, such as fixed-effects regression or propensity score models.

\section{Conclusions}

Consistent with the 2018 AAP stance, the results of this study support the need for pediatricians to urge parents to avoid forms of physical punishment, even parents who have an otherwise positive relationship with their child. This study also contributes to the growing global conversation that indicates that parental use of physical punishment likely creates more harm than benefit to children. Study findings suggest that all children would benefit, even those who have positive mother-child relationships overall, from policies and services put in place to prevent the use of physical punishment and promote positive, nonviolent forms of discipline.

\section{ACKNOWLEDGMENTS}

Funding source: The Fragile Families and Child Wellbeing Study is funded by the Eunice Kennedy Shriver National Institute of Child Health and Human Development (NICHD) (grant numbers R01HD36916, R01HD39135, and R01HD40421), and additional private foundations. The funding sources had no involvement in this study.

\section{References}

1. Sege RD, Siegel BS. Effective discipline to raise healthy children. Pediatrics. 2018. Retrieved from http://pediatrics.aappublications. org/content/early/2018/11/01/peds.2018-3112.abstract.

2. American Academy of Pediatrics (AAP). Guidance for effective discipline. Pediatrics. 1998;101:723-728.

3. Gershoff ET. Corporal punishment by parents and associated child behaviors and experiences: a meta-analytic and theoretical review. Psychol Bull. 2002;128:539-579.

4. Gershoff ET, Grogan-Kaylor A. Spanking and child outcomes: old controversies and new meta-analyses. J Fam Psychol. 2016;30:453469. https://doi.org/10.1037/fam0000191.

5. Paolucci EO, Violato C. A meta-analysis of the published research on the affective, cognitive, and behavioral effects of corporal punishment. J Psychol. 2004;138:197-221. https://doi.org/10.3200/JRLP. 138.3.197-222.

6. The Harris Poll. Four in Five Americans Believe Parents Spanking Their Children is Sometimes Appropriate. New York, NY: 
Harris Insights and Analytics; 2013. Retrieved from: https://theharrispoll.com/new-york-n-y-september-26-2013-to-spank-or-notto-spank-its-an-age-old-question-that-every-parent-must-facesome-parents-may-start-off-with-the-notion-that-i-will-neverspank-my-child-bu/.

7. Ryan RM, Kalil A, Ziol-Guest KM, et al. Socioeconomic gaps in parents' discipline strategies from 1988 to 2011. Pediatrics. 2016;138. https://doi.org/10.1542/peds.2016-0720.

8. Smith, TW, Davern, M, Freese, J, et al., General Social Surveys, 1972-2016[machine-readable data file]/Principal Investigator, Smith, Tom W; Co-Principal Investigators, Peter V. Marsden and Michael Hout; Sponsored by National Science Foundation. -NORC ed.- Chicago: NORC, 2017.

9. Finkelhor D, Turner H, Wormuth BK, et al. Corporal punishment: current rates from a national survey. J Child Fam Stud. 2019; 28:1991-1997. https://doi.org/10.1007/s10826-019-01426-4.

10. Benjet C, Kazdin AE. Spanking children: the controversies, findings, and new directions. Clin Psychol Rev. 2003;23:197-224. https://doi.org/10.1016/S0272-7358(02)00206-4.

11. Bowlby J. Attachment and Loss, Vol. 1: Attachment. New York: Basic Books; 1969.

12. De Wolff MS, van Ijzendoorn H. Sensitivity and attachment: a meta-analysis on parental antecedents of infant attachment. Child Dev. 1997;68:571-591.

13. Fearon RP, Bakermans-Kranenburg MJ, Van IJzendoorn MH, et al. The significance of insecure attachment and disorganization in the development of children's externalizing behavior: a meta-analytic study. Child Dev. 2010;81:435-456.

14. Groh AM, Roisman GI, van IJzendoorn MH, et al. The significance of insecure and disorganized attachment for children's internalizing symptoms: a meta-analytic study. Child Dev. 2012;83:591-610.

15. Hoeve M, Stams GJJ, van der Put CE, et al. A meta-analysis of attachment to parents and delinquency. J Abnorm Child Psychol. 2012;40:771-785.

16. McLoyd VC, Smith J. Physical discipline and behavior problems in African American, European American, and Hispanic children: Emotional support as a moderator. J Marriage Fam. 2002;64:4053. https://doi.org/10.1111/j.1741-3737.2002.00040.x.

17. Bandura A. Aggression: A Social Learning Analysis. Englewood Cliffs, NJ: Prentice Hall; 1973.

18. Lee SJ, Altschul I, Gershoff ET. Does warmth moderate longitudinal associations between maternal spanking and child aggression in early childhood. Dev Psychol. 2013;49:2017-2028. https://doi.org/ 10.1037/a0031630.

19. Altschul I, Lee SJ, Gershoff ET. Hugs, not hits: warmth and spanking as predictors of child social competence. J Marriage Fam. 2016;78:695-714. https://doi.org/10.1111/jomf.12306.

20. Reichman NE, Teitler JO, Garfinkel I, et al. Fragile families: sample and design. Child Youth Serv Rev. 2001;23:303-326.
21. User's Guide for the Fragile Families and Child Wellbeing Study Public Data, Year 3. Princeton, NJ.

22. Achenbach TM, Rescorla LA. Manual for the ASEBA Preschool Forms \& Profiles. Burlington, VT: University of Vermont, Research Center for Children, Youth, \& Families; 2000.

23. Waters E, Deane KE. Defining and assessing individual differences in attachment relationships: Q-methodology and the organization of behavior in infancy and early childhood. In: Bretherton I, Waters E, eds. Monographs of the Society for Research in Child Development: Growing Points in Attachment Theory and Research, 50, Wiley; 1985:41-65.

24. van Ijzendoorn MH, Vereijken CMJL, Bakermans-Kranenburg MJ, et al. Assessing attachment security with the Attachment Q Sort: meta-analytic evidence for the validity of the Observer AQS. Child Dev. 2004;75:1188-1213.

25. Symons D, Clark S, Isaksen G, et al. Stability of Q-sort attachment security from age two to five. Infant Behav Dev. 1998;21: 785-791.

26. Kessler RC, Andrews G, Mroczek D, et al. The World Health Organization Composite International Diagnostic Interview Short Form (CIDI-SF). Int J Methods Psychiatr Res. 1998;7:171-185.

27. Mathieson KS, Tambs K. The EAS temperament questionnaire factor structure, age trends, reliability, and stability in a Norwegian sample. J Child Psychol Psychiatry. 1999;40:431-439.

28. Muthén LK, Muthén BO. Mplus User's Guide, 8th ed. Los Angeles, CA: Muthén \& Muthén; 1998-2017.

29. Kline RB. Principles and Practice of Structural Equation Modeling. 4th ed. New York: Guilford Press; 2016.

30. Satorra A, Bentler PM. Ensuring positiveness of the scaled difference chi-square test statistic. Psychometrika. 2010;75:243. https:// doi.org/10.1007/s11336-009-9135-y.

31. Pace G, Lee S, Grogan-Kaylor A. Spanking and young children's socioemotional development in low- and middle-income countries. Child Abuse Negl. 2019;88:84-95. https://doi.org/10.1016/j. chiabu.2018.11.003.

32. Kochanska G. Children's temperament, mothers' discipline, and security of attachment: multiple pathways to emerging internalization. Child Dev. 1995;66:597-615.

33. Ma J, Grogan-Kaylor A. Longitudinal associations of neighborhood collective efficacy and maternal corporal punishment with behavior problems in early childhood. Dev Psychol. 2017;53:1027-1041. https://doi.org/10.1037/dev0000308.

34. Holden GW, Williamson PA, Holland GWO. Eavesdropping on the family: a pilot investigation of corporal punishment in the home. $J$ Fam Psychol. 2014;28:401-406.

35. Lee SJ, Altschul I, Gershoff L. Wait until your father gets home? Fathers' and mothers' spanking and development of child aggression. Child Youth Serv Rev. 2015;52:158-166. https://doi.org/ 10.1016/j.childyouth.2014.11.006. 